Психология. Журнал Высшей школы экономики, 2016. T. 13. № 1. С. 9-26.

\title{
ДЕКОНСТРУКЦИЯ ГЕТЕРОНОРМАТИВНОЙ МАТРИЦЫ
}

\author{
Д.Д. ИСАЕВ \\ ${ }^{a}$ Клиника «Скандинавия», 191114, Россия, Санкт-Петербург, Литейный пр., д. 55 A
}

\begin{abstract}
Резюме
В работе проводится деконструкция бинарной модели гетеронормативной матрицы через проблематизацию трех ее компонентов: пола, гендера и сексуальной ориентации. Показана детерминированность отношения к телесности (полу) и сексуальности на основе доминирующего бинарного дискурса. Приведены результаты изучения сексуальной ориентации в трех группах сравнения: 94 трансгендерных мужчины, обратившихся для получения разрешения на смену пола, 41 гомосексуальный и 30 гетеросексуальных мужчин. Сексуальная ориентация как целостный психологический конструкт включает в себя ряд подсистем, не всегда совпадающих по направленности. Важным результатом было обнаружение относительной независимости параметра «влюбленность» от направленности влечения. Корреляционный анализ показал, что влечение к лицам своего и противоположного пола носит независимый характер, может быть описано как ортогональная, а не альтернативная модель и для чувственного влечения, фантазий, и для влюбленностей. Получено подтверждение факта, что именно гендерная матрица как социальное предписание довлеет над сексуальностью индивида, самокатегоризация в каждой из групп идет преимущественно через оценку себя «от противного». Срабатывает механизм самопрограммирования и конструирования своей идентичности в соответствии с уже избранной моделью, под которую подстраивают актуальное поведение. Актуальность деконструкции гетеронормативной матрицы состоит в необходимости показать возможность и закономерность сосуществования множества не тождественных друг другу, а вполне равноправных смысловых моделей. Их инаковость должна рассматриваться как нечто самодостаточное, дополнительное, а не взаимоисключающее к любой иной модели отношений. Ослабление жесткой гендерной дихотомии и ломка традиционной системы гендерной поляризации предоставляют возможность для личности обрести и реализовывать ту гендерную идентичность, которая является результатом индивидуального опыта и его творческого переосмысления, соотнесения своих индивидных параметров/желаний с культуральными моделями.
\end{abstract}

Ключевые слова: пол, гендер, сексуальная ориентация, гетеронормативная матрица, бинарная модель.

\section{Гетеронормативная матрица}

Весь мир, в котором мы живем, представляет собой модель или мировоззренческую концепцию и одновременно систему отношений, в которую мы вписаны, но которую мы не замечаем потому, что она кажется нам естественной и привычной. Мы обращаемся к ней, когда нуждаемся в 
объяснении чего-то нового, ее положениями аргументируем свои взгляды или установленные научные факты.

Благодаря усилиям философов, лингвистов и социологов было подтверждено, что в описании любой картины мира лежат бинарные оппозиции, причем они носят универсальный характер (Руднев, 2009).

Бинарная модель, понимаемая как совокупность противоположных и взаимосвязанных сущностей, лежит в основе модернистского мировосприятия и воспроизводится на уровне индивидуального сознания через понятия «мужское» и «женское», телесную данность и противопоставление полов, а также их неизменность. В этой системе координат краеугольным камнем оказывается гендерная матрица, в которой пол/гендер/сексуальность представляют собой единый и неделимый конструкт (Батлер, 2000) (надо заметить, что таковой эта матрица стала представляться лишь последние сто лет, по мере придания особого значения изучению сексуальности). Неизменность гендерного порядка нам пытались внушить классики прошлого: «...разделение труда, которое вначале было лишь разделением труда в половом акте, а потом - разделением труда, совершавшимся само собой или “естественно возникшим” благодаря природным задаткам (например, физической силе), потребностям, случайностям». (Маркс, Энгельс, 1955, с. 30), Также продолжают это делать и многие современные политики и ученые: «Различие полов задано, прежде всего, естественным процессом природной и социальной эволюции, закрепившей за ними определенные и целесообразные функции» (Булычев, 2004).

Жан-Поль Сартр писал, что человек заброшен в определенную ситуацию, он не выбирает ее, но перед ним стоит очень важная задача разобраться в этой ситуации, чтобы в полной мере ощутить свободу и принять ответственность за происходящее с ним (Сартр, 1989). Однако заявленная задача предстает не такой простой, как может показаться. Обращение рядового читателя к научной информации с целью разобраться в проблеме гендера скорее повергает в уныние, чем вселяет оптимизм.

Очень часто мы наблюдаем, что проводимые в психологии и сексологии исследования не содержат какой-либо качественно новой информации, они используют прежний методологический инструментарий, жестко привязанный к старым, хорошо известным эссенциалистским теориям. Тем самым они выполняют функцию верификации уже существующих взглядов, которые вовсе не соответствуют современному уровню понимания гендера и в рамках научного дискурса воспроизводят континуально-биполярную гетеронормативную модель. Кроме того, количественный подход, занимающий доминирующую роль в исследовательской и диагностической практике в отечественной психологии, оказывается не только малопригодным для получения ценной информации понимания гендерных особенностей человека, но и вредным, так как тиражирует и навязывает устаревшие представления. Типичный пример: использование шкалы «Маскулинность - фемининность» 
(5-я шкала) в MMPI или «Полоролевого опросника Сандры Бем» в разных модификациях. Выход из этого методологического тупика может быть найден лишь благодаря использованию качественного подхода, позволяющего осуществлять концептуализацию наблюдаемых фактов с выходом на «теории данного случая» (Семенова, 1998, с. 206). Важнейшим элементом принципиально нового подхода, основанного на попытке выйти за границы доминирующего дискурса, оказывается субъективизация, прочтение индивидуально-личностного своеобразия, а не поиск «универсальных» показателей, определенных качеств и свойств, уже имеющих гендерную маркировку в нашей культуре. Речь не идет об отказе использовать количественные методы, а лишь о необходимости обращаться к реконструкции субъективной картины гендера, например, в рамках психосемантической парадигмы.

Обращаясь к проблемам гетеронормативности, мы вольно или невольно в практической плоскости тестируем идеи Жака Дерриды о децентрации, о разрушении набора «прописных истин», среди которых идеи бинаризма занимают доминирующую позицию. Он показал необходимость «опрокидывания» ценностного ряда иерархически организованных бинарных оппозиций, среди которых оказываются и гетеронормативная матрица и необходимость выхода из замкнутости властных отношений «нормативного центра» и «переферии» (Деррида, 2000a, б). Деконструкция возможна, только если мы сами попытаемся абстрагироваться от привычной системы координат, выйти за рамки привычного дискурса через его проблематизацию.

В рамках гетеронормативной матрицы существует несколько уровней, объединенных концепцией или представлением, которое зафиксировано в биполярной модели, утверждающей существование двух противоположностей, двух полюсов. Первый уровень касается пола, второй - гендера, третий - сексуальности. Проблематизация этих уровней, их сложность и неоднозначность и составляют предмет нашего рассмотрения.

\section{Бинарность пола}

Даже такое простое понятие, как «пол», выглядит вовсе не таким простым, когда встает задача его определения у индивида. Всемирная организация здравоохранения предлагает нормативные показатели, по которым следует определять пол новорожденного: это критерий длины ствола пениса/тела клитора. Девочки - это те, у которых меньше 1 см, а мальчики - те, у которых больше 2.5 см. Результаты измерений должны определять, как будут обращаться с ребенком в дальнейшем, будут его называть девочкой или мальчиком, какое имя дадут. Но уже в нормах обнаруживается существование зоны неопределенности, в которую попадают те, кто на основании измерений располагаются между предлагаемыми 1 и 2.5 см.

К лицам, родившимся с трудноопределяемыми гениталиями по полу, элементами мужской и женской анатомии одновременно, имеющих несовпадение наружных и внутренних половых 
органов или несовпадение анатомии с хромосомным полом, применяется понятие интерсексуальности (устаревший термин - гермафродитизм).

В тех случаях, когда визуально обнаруживались аномалии гениталий при рождении, детей традиционно в возрасте до 3 лет подвергали операции (пластика половых органов), чтобы определиться с полом ребенка и тем самым успокоить окружающих. Но проблема часто не распознается до пубертата, когда у ребенка появляются неожиданные телесные изменения или, напротив, не появляются ожидаемые вторичные половые признаки.

В последние десятилетия стали понимать, что это только внешняя (телесная) часть проблемы. Человек с интерсексуальностью в детстве или подростковом возрасте, а иногда уже и во взрослом возрасте должен выявить и/или определить свою гендерную идентичность. А она вовсе не обязательно совпадает с тем полом, который ему приписали акушеры или посчитали необходимым сделать врачи, хирурги или родители. Более того, выясняется, что определенная часть таких людей вообще не хотели бы говорить о принадлежности к какому-то определенному полюсу $\mathrm{M} / \Phi$, т.е. они хотят находиться вне половой бинарности (выбирают «интерсексуальную идентичность»).

Понимая это, в Германии ради защиты детей от последующих ненужных операций разрешили родителям вписывать в метрику «третий пол», выбрав вариант «неопределенный», а когда ребенок повзрослеет, он сможет самостоятельно указать, к какому полу себя причисляет. Подобная практика избавляет многих детей от возможной стигматизации, опасности гендерного кризиса, связанного с непринятием своего телесного Я.

Эта, казалось бы, сугубо медицинская проблема заставляет задуматься: а где же находится тот «ядерный пол» индивида, который может приводить к отказу от телесной данности? Что первично: голова (психика) или репродуктивные органы?

Мы говорим и верим в неизменное существование только двух полов, но еще 150-200 лет назад считалось, что существует только один пол - мужской. А женщины объявлялись НЕДОмужчиной, т.е. анатомически несовершенной копией мужского организма, а потому слабыми, с разнообразными отклонениями, поэтому у женщин все представлено не так, «как надо». Артур Шопенгауэр в 1851 г. писал, что женщина - это «род промежуточной ступени между ребенком и мужчиной, который и есть собственно человек» (Шопенгауэр, 1990, с. 288). Но даже после «обнаружения» женского пола он все равно рассматривался всегда как что-то вторичное, подчиненное, зависимое и одновременно антагонистичное по отношению к мужскому.

Исследования в XX в. привели сначала к выделению социокультурной составляющей пола - гендеру, а затем и к пониманию того, что даже биологические характеристики пола являются социально сконструированными, т.е. все анатомо-физиологическое многообразие произвольно отнесено к одному или другому полюсу мужского или женского. Пол оказывается социальной категорией, которая приписывается биологическому организму, и зачастую это приписывание 
никак не связано с видимыми анатомо-морфологическими особенностями человека (Воронцов, 2003). Для человека биологический пол всегда существует только как условная система объяснений, т.е. как метафора, которая выполняет роль культурно-формирующего фактора (Чумаков, 2010). Биологическая природа пола представляет собой искусственно созданную иллюзию, утвержденную властным дискурсом. Та данность, которую мы привыкли называть полом, «сама есть исторический конструкт и на самом деле является политической категорией» (Батлер, 2005, с. 302). В самой оппозиции «мужское - женское» заключена возможность использовать пол и для четкой маркировки границы между Своими и Чужими, и для продуцирования отношений неравенства и контроля (Рябова, 2008а). К полу апеллируют, поскольку он легко идентифицируется человеком, стереотипные представления о характеристиках мужчин и женщин легко соотносятся с личным опытом, отношения полов воспринимаются как самые очевидные, понятные, а потому легитимные (Там же). Одновременно натурализация пола оказывается одним из средств для навязывания гетеронормативной гендерной идентичности: «Человек должен вести себя, одеваться, говорить, думать, как подобает женщине/мужчине, потому что является человеком женского/мужского пола, то есть потому, что этот человек есть женщина/мужчина» (Хитрук, 2012, с. 44).

\section{Бинарность гендера}

Второй блок в рассматриваемой матрице занимает понятие «гендер».
Сам термин впервые появился в работах сексолога Джона Мани в 1955 г., когда он столкнулся с необходимостью описывать психологические качества лиц с неясно определяемым полом и транссексуалов. При помощи нового термина («гендера») была предпринята попытка провести структурное отделение природного (генетических, физиологических и репродуктивных характеристик) от приобретенного (культурного) в человеке.

В настоящее время существует два кардинально противоположных подхода к пониманию гендера. В классической (эссенциалистской) парадигме, которой придерживаются очень многие отечественные медики и психологи, пол (биологические различия) рассматривается как природная основа, первопричина психологических и социальных различий между женщинами и мужчинами. А гендер («психологический пол»), выраженный в конструкте «маскулинность/феминность», понимается как комплекс качеств, объективно присущих индивиду, проявления которых регулируются культурой. Одновременно это и достигаемый социальный статус, который связан с исполнением определенных социальных ролей.

Конструктивистский подход рассматривает маскулинность/феминность как продукт культуры; согласно этому подходу, гендерные характеристики индивида не зависят от пола, а представляют набор установок, ролей, норм поведения, иерархию ценностей, свойственных мужскому или женскому полу в каждом конкретном обществе. При этом маскулинность и феминность понимаются не 
как черты или роли, а как характеристики взаимодействия субъектов, которые подвергаются гендерной оценке. Гендер в социальном взаимодействии выступает только как когнитивная схема, в виде обусловленных культурой представлений о том, какие личностные признаки свойственны людям того или иного пола (Воронцов, 2008).

Важно понимать, что гендер конструируется не только самим обществом, но и каждым конкретным человеком. Усваивая и принимая определенные правила с раннего детства, люди уже не мыслят себя вне определенных рамок, конструируют на их основе свой собственный образ (гендерный дисплей), воспроизводят отношения, которые относятся к гетеронормативным. Конструирование гендерного сознания индивидов происходит посредством распространения и поддержания социальных и культурных стереотипов, норм и предписаний, за соблюдением которых общество в лице его членов внимательно следит. В своем поведении, в реализуемых социальных ролях индивиды выстраивают гендер как для себя, так и для окружающих.

Гендерные стереотипы обладают ярко выраженными эмоциональнооценочными характеристиками. Все, что определяется как мужское, рассматривается в качестве позитивного и доминирующего, «мужскими» называются характеристики, соотносимые, как правило, с позициями власти и управления, а женское рассматривается в качестве негативного и периферийного (Чумаков, 2010). Работу по систематизации зарубежного и отечественного опыта, в которой представлены разнообразные взгляды и теории по этому вопросу, опубликовали недавно гендерные социологи (Здравомыслова, Тёмкина, 2015). Подобного рода иерархизированность мужского и женского, андроцентризм помогает поддерживать властные отношения и социальную организацию общества в целом (Рябова, 2008б) - в этом смысл и назначение гетеронормативной матрицы. «Естественность» мужского господства, как и «естественность» противостояния полов, есть результат длительной мифологизации, которая требует бесконечного ритуализованного повторения определенных ментальных установок, их воспроизводства в межличностном взаимодействии, внедрения в самосознание и тело социальных агентов (Хитрук, 2014). С одной стороны, понятие маскулинности и феминности являются историческим и культурным вымыслом, но эти вымыслы становятся психологической реальностью, как только они институционализируются доминирующим гетеронормативным дискурсом, овладевают умами каждого члена социума. Бинарность ментальных установок, как и бинарность внешнего социального порядка, находит свое подтверждение и «естественную» реализацию в телах людей, которые превращаются в носителей субъективно-объективной дихотомии и демонстрируют, таким образом, нерушимый «природный» характер гендерной поляризации и субординации (Там же).

«Программируемая субъективность» превращается в гендерную идентичность, которая отражает внутреннее самосознание, неразрывно связана с восприятием себя и 
лежит в основе мировосприятия. В рамках подобного подхода становится очевидной тотальная сконструированность и предопределенность субъекта метанарративом, его субординированность по отношению к властной структуре (Агафонова, 2005). Именно гендер выступает в форме метанарратива, в задачу которого входит объяснение и иерархическое выстраивание множества локальных нарративов. Вопреки «здравому смыслу» подобный подход показывает обусловленность восприятия пола от гендера (доминирующей гендерной схемы), а не наоборот.

Однако такой подход встречает ожесточенное сопротивление. Проблема соотношения «природного» и «культурального» до сих пор остается чрезвычайно удобным вопросом для обвинения социологов, философов и психологов в том, что природное есть, но якобы игнорируется обществоведами и гендерными психологами, так как «они просто не знают и не изучают природные различия полов». Вроде как «конструктивизм - это хорошо», но именно природа берет свое и делает из мальчиков - мужчин, а из девочек - женщин, при этом в качестве доводов приводятся самые разные и далеко не всегда корректные исследования. Сложно было бы что-либо возразить, если не учитывать того факта, что природные задатки намного более разнообразны и вариативны в своей потенциальности к развитию, чем то, что из них хочет и может сделать современная культура. Разнообразие психологических и социальных характеристик женщин и мужчин, принципиальное тождество биологи- ческих характеристик людей позволяет сделать вывод о том, что биологический и соматический пол не может быть объяснением различий их социальных ролей, существующих в разных обществах (Воронина, 2002). Говоря иначе, каждый человек обладает значительно бо́льшим диапазоном способностей и возможностей, чем он развивает в себе к периоду зрелости, в соответствии с тем, что оказывается востребовано культурой и соответствует гендерным нормативам. Социальная заданность гендерных проявлений постоянно дисциплинирует индивида, навязывает границы существования Я на всех уровнях, вызывая ощущение их «естественности» и «природности». Но так же, как родной язык становится таковым лишь в процессе его усвоения, так и гендер обретается через присвоение когнитивных гендерных схем (линз гендера) и в процессе выполнения предписанных гендерных ролей и воспроизводства гендерного дисплея.

\section{Бинарность сексуальной ориентации}

Гендерная матрица не может быть рассмотрена без разбора вопроса о сексуальной составляющей. В гетеронормативных контекстах допустимой идентичностью считается лишь гетеросексуальная идентичность (Rosenfeld, 2009). А сама гетеросексуальность культивируется через запреты, которые оправдываются стремлением сохранить общество как систему биологического воспроизводства (Пырьянова, 2014).

Однако и в вопросе о сексуальной ориентации все выглядит не так 
однозначно. Традиционная дихотомия «гомо - гетеро» при ближайшем рассмотрении оказывается жестко привязанной к устаревшим бинарным моделям. Даже предлагаемые в последние годы определения подчеркивают эту неоднозначность и проблемность. Сексуальная ориентация характеризует отклик человека на гендерно окрашенные стимулы. Человек может испытывать сексуальное и/или эмоциональное влечение только к женщинам (не ко всем подряд), только к мужчинам (не ко всем подряд), и к мужчинам, и к женщинам, и/или к интерсексуалам, трансвеститам, трансгендерам и другим людям, не вписывающимся в существующие гендерные нормы. Некоторые люди безразличны к гендерно окрашенным стимулам и могут считаться асексуальными (Benestad, 2002).

В качестве классификационных критериев сексуальной ориентации могут использоваться: актуальное сексуальное поведение (например, количество партнеров своего и противоположного пола); имеющиеся чувства (например, фантазии и желания); самокатегоризация людей (кем они себя считают) (Laumann et al., 1994), а также генитальные или мозговые реакции (физиологические измерения возбуждения в ответ на мужские и женские образы) (Wilson, Rahman, 2005). Практически всегда в качестве определяющих в литературе ссылаются на один или оба компонента: «поведенческий» и «психологический» (Sell, 2007).

В течение последних 60 лет самым распространенным инструментарием для измерения сексуальной ориентации была биполярная шкала Кинзи. Однако на современном этапе развития науки сексуальная ориентация переосмысливается с позиции социального конструктивизма. В рамках подобного подхода ориентация оказывается не столько природной данностью, сколько интерпретацией действий и чувств индивида. И именно общество задает конкретный смысл (и название) поведению и чувствам (Dixon, 2005).

Прежние представления о сексуальной ориентации нуждаются в пересмотре и проверке. Например, Л. Гарнетс (Garnets, 2002) указывает на четыре принципиальные позиции, нуждающиеся в ревизии. Во-первых, сексуальную ориентацию надо рассматривать не как биполярную дискретную шкалу, а как два отдельных и независимых измерения, в разной степени и интенсивности связанных с привлекательностью мужчин и привлекательностью женщин. Вовторых, не столько сексуальное поведение определяет сексуальную ориентацию (как считалось ранее), но также фантазии, эмоциональные привязанности, статус текущих отношений и самоидентификация. В-третьих, новая парадигма допускает несогласованность между желаниями, поведением и сексуальной идентичностью. В-четвертых, сексуальная ориентация вовсе не обязательно должна быть стабильной и неизменной в течение жизни. Большая пластичность и изменчивость сексуальной ориентации оказывается характерной скорее для женщин, чем для мужчин (Baumeister, 2000).

Не отрицая факта самого существования сексуальной ориентации, следует признать, что смысловое 
наполнение этой категории (как самокатегоризация, так и приписывание) выстраивается преимущественно на основе доминирующего общественного дискурса, и далеко не факт, что соответствует тем результатам, которые могут показать специально сконструированные исследования.

\section{Эмпирический анализ компонентов сексуальной ориентации}

\section{Метод}

Для изучения компонентов, лежащих в основе сексуальной ориентации, были использованы «Опросник чувственных предпочтений» (32 пункта) и «Опросник привлекательности и отвержения» (16 пунктов) (Dixon, 2005, перевод автора). В них предлагалось оценить частоту и интенсивность переживаний эротических фантазий, влечения, влюбленностей и контактов в течение жизни и в актуальный период времени (за последний месяц) к лицам мужского и женского пола по отдельности. Помимо этого, были представлены вопросы об эмоциональном восприятии возможности эротических снов, сексуальных действий или внимания со стороны привлекательного/непривлекательного лица мужского и женского пола, а также возможности активной/пассивной роли в эротическом контакте.

Выборку исследования составили 165 человек в трех группах сравнения: 94 трансгендерных мужчины, обратившихся для получения разрешения на смену пола, а также 41 гомосексуальный и 30 гетеросексу- альных (по самоидентификации) мужчин. Возраст респондентов составлял от 18 до 35 лет. Исследование проводилось в 2012-2013 гг. в Санкт-Петербурге, ранее представлялись лишь предварительные результаты сравнения двух групп. Данные опросников соотносились с результатами, полученными по методике «Универсальный трехфакторный семантический дифференциал» в нашей модификации (Исаев, 2012), математическая обработка включала корреляционный и факторный анализ.

\section{Результать}

Сравнительный анализ среднегрупповых данных по показателям самокатегоризации выявил, что в группе гетеросексуалов исключительно гетеросексуальными считают себя 90\%, а остальные - преимущественно гетеросексуальными. В группе гомосексуальных мужчин лишь 48.8\% считали себя исключительно гомосексуальными, более половины признавали себя преимущественно гомосексуальными или даже бисексуальными (4.9\%). Таким образом, оказывается, что гомосексуальная группа даже на уровне самосознания выглядит как континуум между бисексуальностью и исключительной гомосексуальностью. В группе трансгендерных мужчин (биологических женщин) были получены все варианты ответов от «исключительной гетеросексуальности» до «исключительной гомосексуальности». В этой группе только 57.4\% считали себя исключительно гетеросексуальными (испытывали влечение к лицам своего биологического пола), 
а остальные довольно равномерно располагались по шкале А. Кинси (таблица 1).

Как показали результаты, вопреки бытующему в обществе представлению, гетеросексуальные мужчины обретают уверенность в своей гетеронормативности не через наличие влечения к противоположному полу, а на основе отсутствия гомосексуальных переживаний и контактов. Ощущение себя исключительно гетеросексуальным позволяет им, в свою очередь, чувствовать себя увереннее и увеличивает уровень притязаний в сторону большей доминантности, стеничности, «мужественности».

Самокатегоризация гомосексуальных мужчин осуществлялась на основе анализа отсутствия гетероэротических чувств, влечения, а не интенсивности переживания гомоэротических устремлений (картина зеркальная по отношению к гетеросексуалам). Их отличает от гетеросексуальных мужчин то, что они ориентируются исключительно на чувства, а не на контакты.

Трансгендерные лица демонстрируют бо́льшую вариативность в сек- суальной ориентации, однако для них она также оказывается важным способом оценивать свою гендерную нормативность в соответствие с избранным мужским гендером. Они отрицают эротические фантазии, влюбленности и влечение к мужскому полу - это оказывается для них очень значимым показателем, при одновременном существовании не всегда осознаваемого влечения к мужскому полу. Соответствие «нормативной» сексуальной идентичности повышает уверенность трансгендерных мужчин в себе, увеличивает значимость партнерских отношений, в которых они хотели бы видеть партнершу более феминную, зависимую, ведомую, соответствующую традиционной гендерной схеме. Одновременно декларация своей нормативности с точки зрения направленности влечения сочеталась с тенденцией к негативному восприятию гомосексуальности.

Таким образом, трансгендерные мужчины не только решают психологическую задачу отвержения интереса к мужскому полу, но и нацелены

Таблица 1

Частотное распределение самокатегоризации сексуальной ориентации по шкале А. Кинси (в \%)

\begin{tabular}{|c|c|c|c|c|c|c|c|}
\hline $\begin{array}{c}\text { Обследованные } \\
\text { группы }\end{array}$ & 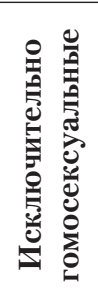 & 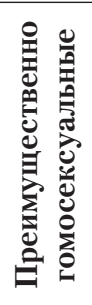 & 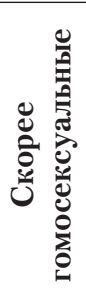 & 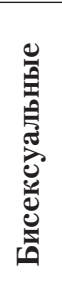 & 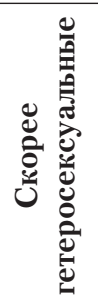 & 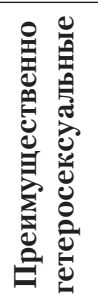 & 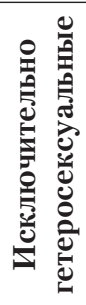 \\
\hline Трансгендеры & 57.4 & 10.6 & 8.5 & 7.4 & 8.5 & 5.3 & 2.1 \\
\hline Гомосексуалы & 48.8 & 36.6 & 9.8 & 4.9 & & & \\
\hline Гетеросексуалы & & & & & 3.3 & 6.7 & 90.0 \\
\hline
\end{tabular}


на нахождение у себя «нормативного» (с точки зрения желаемого гендера) влечения к женскому полу.

Корреляционный анализ (ранговая корреляция Спирмена) показал, что влечение к лицам своего и противоположного пола носит независимый характер, может быть описано как ортогональная, а не альтернативная модель и для чувственного влечения, фантазий, и для влюбленностей (рисунки 1, 2). Отличную от этого модель (на когнитивном уровне) демонстрируют лишь трансгендерные мужчины, которые ориенти- рованы на построение патриархатной гендерной матрицы, в которой гендер и сексуальность связаны в единый жестко согласованный конструкт (рисунок 3).

\section{Обсуждение}

Сексуальная ориентация как целостный психологический конструкт включает в себя ряд подсистем, не всегда совпадающих по направленности. В этих случаях начинает срабатывать механизм самопрограммирования и конструи-

Рисунок 1

Соотношение направленности влечения на мужчин и женщин у гетеросексуальных мужчин $(\mathrm{p}<0.05)$

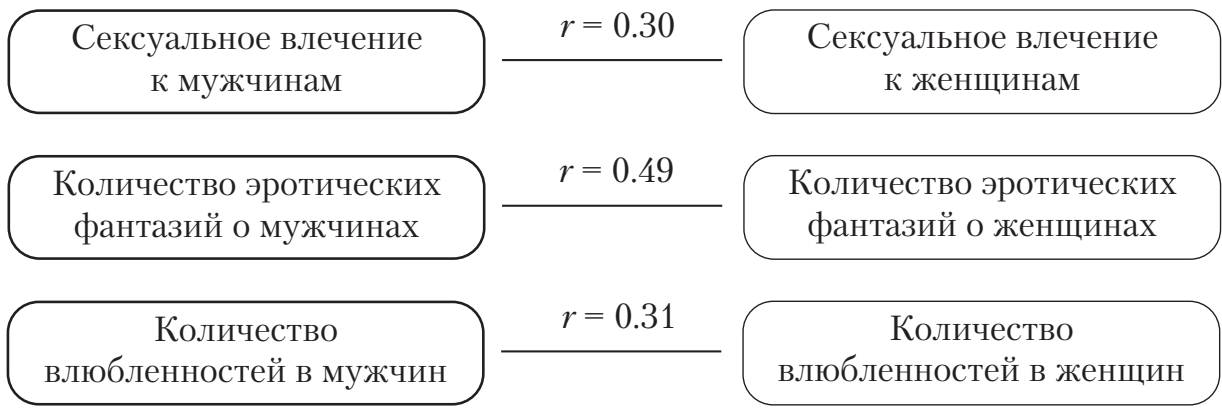

Рисунок 2

Соотношение направленности влечения на мужчин и женщин у гомосексуальных мужчин $(\mathrm{p}<0.05)$

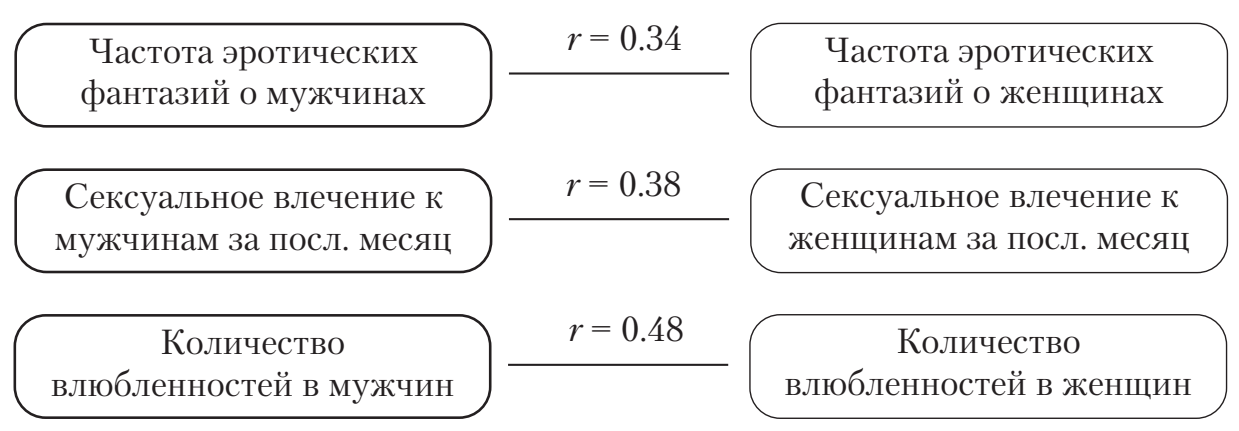


Рисунок 3

Соотношение направленности влечения на мужчин и женщин у трансгендерных мужчин $(\mathrm{p}<0.05)$

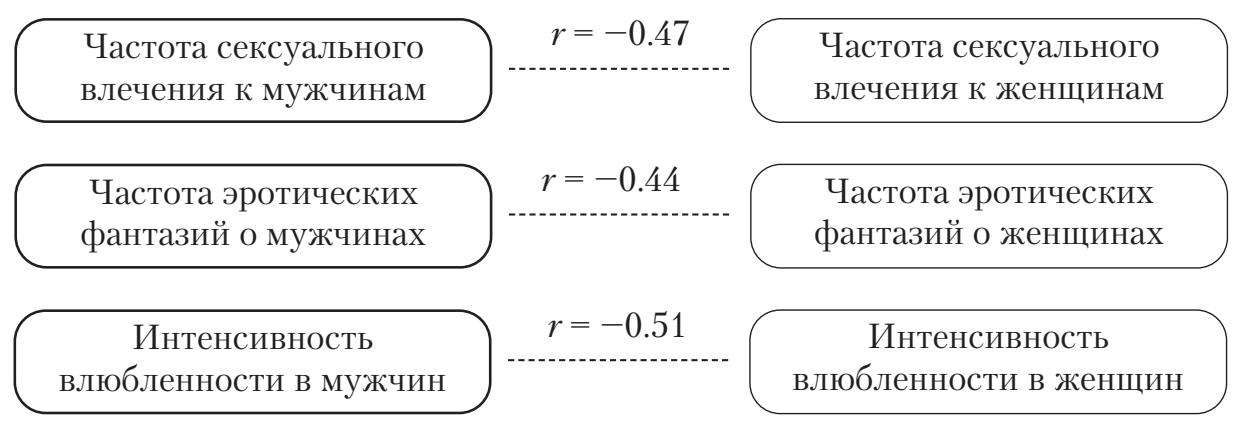

рования своей идентичности в соответствии с уже избранной моделью, под которую подстраивают актуальное поведение, даже если это не в полной мере соответствует чувственной природе данного индивида (McKnight, 1997). Важным результатом было обнаружение относительной независимости параметра «влюбленность», который образует отдельный фактор и не входит в структуру сексуальной ориентации в рассматриваемых группах.

В своем исследовании мы получили подтверждение того факта, что именно гендерная матрица как социальное предписание довлеет над сексуальностью индивида, поэтому гетеросексуальность превращается, прежде всего, в форму доказательства своей «мужественности», нормативности и, в конечном счете, социальной комформности, приверженности властному дискурсу. «Культуральные представления и социальное давление направляют сексуальные чувства и поведение в определенном направлении» (Kauth, 2000 , p. 191), что и было подтверждено на нашей выборке. Очевидным оказывается, что самокатегоризация в каждой из групп идет преимущественно через оценку себя «от противного», одновременно была получена картина тесной взаимообусловленности «гомо - гетеро» полюсов.

Как и в случае с телесностью, гендер является определяющим для маркирования сексуальной ориентации: гендерные характеристики, проявляемые в межличностном взаимодействии, а не пол реальных сексуальных партнеров являются сигнификатом сексуальной ориентации человека в социуме. Общество склонно декларировать жесткую взаимосвязь между отклонением от гендерного дисплея и сексуальной атипией. Как известно, к ЛГБТ-сообществу приписывают исключительно на основе каких-то внешних, весьма неоднозначных признаков.

Деконструкция бинарной гендерной модели угрожает разрушить фундаментальные основы доминирующего консервативного дискурса, опирающегося на эссенциалистскую парадигму «обыденного» сознания, и привести к фундаментальному (либеральному) перевороту, в котором 
системообразующим является не бинарный порядок, а индивидуальная вариативность и креативность. Именно они могут лечь в основу благополучия общества, в котором человек окажется высшей ценностью. С этой точки зрения решение проблемы гетеронормативности приобретает особое значение в борьбе прогрессивных и консервативных тенденций. «Консервативный дискурс объяснил всем, что гендер разрушает семью, гетеросексуальность, нацию» (Тёмкина, 2015). Говоря иначе, интуитивно понимая, что именно гендер является «большим нарративом», приверженцы консервативных взглядов пытаются оградить людей от знания механизмов работы гендера, тем самым добиваясь консервации системы власти и неравенства, которая им кажется очень комфортной. Дискурс умолчания очень удобен и активно используется неоконсерваторами не только в вопросе о сексуальных меньшинствах, но и в проблемах, поднимаемых феминизмом, так как это способ избежать осознания нарратива, который, как и любой текст, может быть отредактирован и даже переписан (воспроизводство доминирующего дискурса посредством «умолчания» - см.: Радина, 2007). Но то, что не осознается людьми, не стало отрефлексированным нарративом, переписать, конечно, невозможно. Принятие бинарной/биполярной социальной модели основывается на бессознательном беспроблемном восприятии когнитивных схем, которые не подвергаются рефлексии. Индивид принимает данные схемы как данность, исходя из ощущения, что они являются единственно воз- можными. Проблематизация возникает лишь в результате гендерного кризиса (несовпадения собственных потребностей и требований доминирующего дискурса) или в процессе выстраивания индивидуального нарратива, ориентированного на индивидуальное своеобразие.

\section{Выводы: переосмысление гендера и сексуальности}

Утверждение актуальности задачи деконструкции гетеронормативной матрицы состоит вовсе не в желании «перевернуть отношения», унизить или отвергнуть гетеросексуальность (на что спекулятивно пытаются намекать радетели «традиционных ценностей»), а в необходимости показать возможность и закономерность сосуществования множества не тождественных друг другу, но вполне равноправных смысловых моделей. Их инаковость должна рассматриваться как нечто самодостаточное, дополнительное, а не взаимоисключающее относительно любой иной модели отношений.

Вслед за постструктуралистами можно сказать, что настоящее субъекта (богатство Я) образуется в результате взаимодействия с тем, чем он сам не является. Чем шире это взаимодействие и больше соприкосновение с иным (Другим), тем личностно богаче оказывается внутренний мир человек и креативнее его бытие. Мы обречены жить в мире, где все разные и непохожие, но это позволяет нам самим становиться духовно богаче и осознавать свою уникальность.

Дегендеризация общества, которой нас так часто пугают, означает не 
одинаковость женщин и мужчин, а возможность освободиться от гендерных шаблонов и приобрести бо́льшую адаптивность и изменчивость в быстро меняющемся мире на основе максимального использованиям своих индивидуальных задатков, «полнее и глубже стать собой» (Киммел, 2006). Ослабление жесткой гендерной дихотомии и ломка традиционной системы гендерной поляризации предоставляют возможность для личности обрести и реализовывать ту гендерную идентичность, которая выстроена не на основе пассивного усвоения норм и требований гендерной роли, а является результатом индивидуального опыта и его творческого переосмысления, соотнесения своих индивидных параметров/желаний с культуральными моделями.

\section{Литература}

Агафонова, Е. В. (2005). Перспективы субъективности в контексте нарративной проблематики (Автореферат кандидатской диссертации, Томский государственный университет, Томск).

Батлер, Дж. (2000). Гендерное беспокойство. В кн. Е. Гапова (Ред.), Антология гендерной теории (с. 297-346). Минск: Пропилеи.

Батлер, Дж. (2005). Присвоение телом гендера: философский вклад Симоны де Бовуар. В кн.: Женщины, познание и реальность: Исследования по феминистской философии (с. 292-303). М.: РОССПЭН.

Булычев, И. И. (2004). Образы маскулинности и феминности в формате гендерной картины мира. Credo пег. Теоретический журнал, 1. Режим доступа: http://credonew.ru/content/view/384/56/

Воронина, О. А. (2002). Гендер. В кн. А. А. Денисова (Ред.), Словарь гендерных терминов (с. 21-24). М.: Информация XXI век.

Воронцов, Д. В. (2003). Социальная психология пола. Методические указания к спецкурсу «Основы гендерной психологии». Ростов-на-Дону: Изд-во Ростовского государственного университета.

Воронцов, Д. В. (2008). Гендерная психология общения. Ростов-на-Дону: Изд-во Южного федерального университета.

Деррида, Ж. (2000а). Письмо и различие. СПб.: Академический проект.

Деррида, Ж. (2000б). Структура, знак и игра в дискурсе гуманитарных наук. В кн. Г. К. Косиков (Сост.), Франиузскал семиотика: От структурализма к постструктурализму (с. 407-420). М.: Издательская группа «Прогресс».

Здравомыслова, Е. А., Тёмкина, А. А. (2015). 12 лекиий по гендерной социологии. Уиебное пособие. СПб.: Изд-во Европейского университета в Санкт-Петербурге.

Исаев, Д. Д. (2012). Психологическое понимание и измерение пола. Учебное пособие. СПб.: Изд-во СПбГПМу.

Киммел, М. (2006). Гендерное общество. М.: РОССПЭН.

Маркс, К., Энгельс, Ф. (1955). Немецкая идеология. В кн. К. Маркс, Ф. Энгельс, Сочинения (2-е изд., т. 3, с. 7-544). М.: Изд-во политической литературы.

Пырьянова, О. А. (2014). Феномен фигуративной сексуальности: сущность и репрезентащия (Кандидатская диссертация, Уральский федеральный университет имени первого Президента России Б.Н. Ельцина, Екатеринбург). 
Радина, Н. К. (2007). Молчание как действие: технологии воспроизводства расистского дискурса в процессе преподавания в высшей школе. В кн. В. Воронков, О. Карпенко, А. Осипов (Ред.), Расизм в языке образования (с. 131-135). СПб.: ЦНСИ.

Руднев, В. П. (2009). Энциклопедический словарь культуры ХХ века. Ключевые понятия и тексты. М.: Аграф.

Рябова, Т. Б. (2008а). Пол власти: гендерные стереотипы в современной российской политике. Иваново: Ивановский государственный университет.

Рябова, Т. Б. (2008б). Гендерные стереотипы как фактор оценки субъектов политического процесса. Женщина в российском обществе, 2, 44-52.

Сартр, Ж.-П. (1989). Экзистенциализм - это гуманизм. В кн. А. А. Яковлев (Ред.), Сумерки богов (с. 319-344). М.: Политиздат.

Семенова, В. (1998). Качественные методы: введение в гуманистическую социологию. М.: Добросвет.

Тёмкина, А. А. (2015). Гендер, секс и феминизм: взгляд социолога. Режим доступа: http://arzamas.academy/ materials/959

Хитрук, Е. Б. (2012). «Существует ли женщина?»: деконструкция женской субъективности и телесности в философии постмодерна. Вестник Томского государственного университета, $361,39-44$.

Хитрук, Е. Б. (2014). Символическое насилие как основной механизм воспроизводства гендерной поляризации и субординации в теории П. Бурдье. Вестник Томского государственного университета, 388, 81-85.

Чумаков, В. И. (2010). Гендерология и феминология. Учебно-методическое пособие для студентов. Волгоград: Изд-во ВолГМУ.

Шопенгауэр, А. (1990). Афоризмы и максимы. Л.: Изд-во Ленинградского государственного университета.

Baumeister, R. F. (2000). Gender differences in erotic plasticity: the female sex drive as socially flexible and responsive. Psychological Bulletin, 126(3), 347-374.

Benestad, E. E. P. (2002). Gender belonging: Children, adolescents, adults and the role of the therapist. In Queer Counselling and Narrative Practice (pp. 204-225). Adelaide: Dulwich Centre Publications.

Dixon, S. A. (2005). Sexual orientation identity as cultural construct: Toward a social constructionist understanding (PhD dissertation). Antioch New England Graduate School, Keene, NH.

Garnets, L. D. (2002). Sexual orientations in perspective. Cultural Diversity and Ethnic Minority Psychology, 8(2), 115-129.

Kauth, M. R. (2000). True nature: A theory of sexual attraction. New York: Kluwer Academic/Plenum Publishers.

Laumann, E. O., Gagnon, J. H., Michael, R. T., \& Michaels, S. (1994). The social organization of sexuality: Sexual practices in the United States. Chicago: University of Chicago Press.

McKnight, J. (1997). Straight science? Homosexuality, evolution and adaptation. London: Routledge.

Rosenfeld, D. (2009). Heteronormativity and homonormativity as practical and moral resources: The case of lesbian and gay elders. Gender and Society, 23(5), 617-638.

Sell, R. L. (2007). Defining and measuring sexual orientation for research. In The health of sexual minorities: Public health perspectives on lesbian, gay, bisexual and transgender populations (pp. 355-374). New York: Springer. 
Wilson, G., \& Rahman, Q. (2005). Born gay: The psychobiology of sex orientation. London: Peter Owen Publishers.

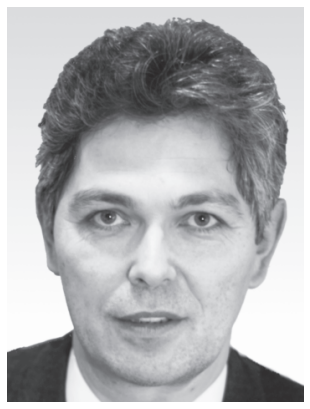

Исаев Дмитрий Дмитриевич - врач-психотерапевт, клиника «Скандинавия», кандидат медицинских наук.

Контакты: dr.disaev@gmail.com

\title{
Deconstruction of Heteronormative Matrix
}

\author{
Dmitry D. Isaev ${ }^{a}$ \\ a "Scandinavia" clinic , 55A Liteinyi pr., St Petersburg, 191114, Russian Federation
}

\begin{abstract}
The deconstruction of the binary model of heteronormative matrix through problematization of its three components: sex, gender and sexual orientation is performed in the present article. The determination of attitude towards corporeality (sex) and sexuality is shown on the basis of the dominant binary discourse. The author cites the results of the study on sexual orientation in three comparison groups: 94 transgender men, who appealed for permission to change their sex, 41 homosexual and 30 heterosexual men. Sexual orientation as a holistic psychological construct includes several subsystems, which are not always coincide in their orientation. The important result was the discovery of a relative independence of the parameter "falling in love" from the orientation of impulse. Correlational analysis showed that attraction to people of own and opposite sex has independent character, may be described as orthogonal and not alternative model for both sensual attraction, fantasies and falling in love. The fact is confirmed that it is exactly gender matrix as a social order that prevails over sexuality of individual, and self-categorization in each group occurs mostly through evaluation of self ex contrario. The mechanism of self-programming and construction of own identity in line with the already chosen model activates, to which the actual behavior is tuned. The urgency of deconstruction of the heteronormative matrix consists of the necessity to show the possibility and legitimacy of coexistence of the many non-identical, but fairly equal in rights meaning models. Their otherness should be considered as something self-sufficient, additional, and not mutually exclusive to any other model of relationships. The weakening of the hard gender dichotomy and the breakdown of the traditional system of gender polarization gives possibility for a personality to acquire and realize gender identity, which is the result of the individual experience and its creative rethinking, of correlation of one's individual parameters/ desires with cultural models.
\end{abstract}

Keywords: sex, gender, sexual orientation, heteronormative matrix, binary model. 


\section{References}

Agafonova, E. V. (2005). Perspektivy sub"ektivnosti v kontekste narrativnoi problematiki [The perspectives of subjectivity in the context of narrative problematics] (Extended abstract of PhD dissertation, Tomsk State University, Tomsk, Russian Federation).

Baumeister, R. F. (2000). Gender differences in erotic plasticity: the female sex drive as socially flexible and responsive. Psychological Bulletin, 126(3), 347-374.

Benestad, E. E. P. (2002). Gender belonging: Children, adolescents, adults and the role of the therapist. In Queer Counselling and Narrative Practice (pp. 204-225). Adelaide: Dulwich Centre Publications.

Bulychev, I. I. (2004). Obrazy maskulinnosti i feminnosti v formate gendernoi kartiny mira [The images of masculinity and femininity in the format of gender worldview]. Credo new. Teoreticheskii Zhurnal, 1. Retrieved from http://credonew.ru/content/view/384/56/

Butler, J. (2000). Gendernoe bespokoistvo [Gender dysphoria]. In E. Gapova (Ed.), Antologiya gendernoi teorii [The anthology of gender theory] (pp. 297-346). Minsk: Propilei.

Butler, J. (2005). Prisvoenie telom gendera: filosofskii vklad Simony de Bovuar [The acquisition of gender by body: the philosophical contribution of Simone de Beavoir]. In Zhenshchiny, poznanie $i$ real'nost': Issledovaniya po feministskoi filosofii [Women, cognition and reality: Studies in feminist philosophy] (pp. 292-303). Moscow: ROSSPEN.

Chumakov, V. I. (2010). Genderologiya i feminologiya [Genderology and feminology]. Volgograd: Volgograd State Medical University.

Derrida, J. (2000a). Pis'mo i razlichie [Writing and difference]. Saint Petersburg: Akademicheskii proekt. (Transl. of: Derrida, J. (1979). L'ecriture et la difference. Paris: Seuil. (in French).)

Derrida, J. (2000b). Struktura, znak i igra v diskurse gumanitarnykh nauk [Structure, sign and play in the discourse of humanitarian sciences]. In G. K. Kosikov (Ed.), Frantsuzskaya semiotika: Ot strukturalizma $k$ poststrukturalizmu [French semiotics: From structuralism to poststructuralism] (pp. 407-420). Moscow: Publishing Group "Progress".

Dixon, S. A. (2005). Sexual orientation identity as cultural construct: Toward a social constructionist understanding (PhD dissertation). Antioch New England Graduate School, Keene, NH.

Garnets, L. D. (2002). Sexual orientations in perspective. Cultural Diversity and Ethnic Minority Psychology, 8(2), 115-129.

Isaev, D. D. (2012). Psikhologicheskoe ponimanie i izmerenie pola [Psychological understanding and dimension of gender]. Saint Petersburg: Saint Petersburg State Pediatric Medical University.

Kauth, M. R. (2000). True nature: A theory of sexual attraction. New York: Kluwer Academic/Plenum Publishers.

Khitruk, E. B. (2012). Does woman exist?: Deconstruction of female subjectivity and physicality in philosophy of postmodernism. Tomsk State University Journal, 361, 39-44.

Khitruk, E. B. (2014). Symbolic violence as the main mechanism for the reproduction of gender polarization and subordination in the theory of Pierre Bourdieu. Tomsk State University Journal, 388, 81-85.

Kimmel, M. (2006). Gendernoe obshchestvo [The gendered society]. Moscow: ROSSPEN. (Transl. of: Kimmel, M. (2000). The gendered society. New York: Oxford University Press.)

Laumann, E. O., Gagnon, J. H., Michael, R. T., \& Michaels, S. (1994). The social organization of sexuality: Sexual practices in the United States. Chicago: University of Chicago Press.

Marx, K., \& Engels, F. (1955). Nemetskaya ideologiya [The german ideology]. In K. Marx \& F. Engels, Sochineniya [Writings] (2nd ed., Vol. 3, pp. 7-544). Moscow: Izdatel'stvo Politicheskoi Literatury. McKnight, J. (1997). Straight science? Homosexuality, evolution and adaptation. London: Routledge. 
Pyryanova, O. A. (2014). Fenomen figurationoi seksual'nosti: sushchnost' i reprezentatsiya [The phenomenon of figurative sexuality: Essence and representation] (PhD dissertation, Ural Federal University, Yekaterinburg, Russian Federation).

Radina, N. K. (2007). Molchanie kak deistvie: tekhnologii vosproizvodstva rasistskogo diskursa v protsesse prepodavaniya $\mathrm{v}$ vysshei shkole [Silence as action: the technologies of reproduction of the racist discourse]. In V. Voronkov, O. Karpenko, \& A. Osipov (Eds.), Rasizm v yazyke obrazovaniya [Racism in the language of education] (pp. 131-135). Saint Petersburg: Centre for Independent Social Research.

Rosenfeld, D. (2009). Heteronormativity and homonormativity as practical and moral resources: The case of lesbian and gay elders. Gender and Society, 23(5), 617-638.

Rudnev, V. P. (2009). Entsiklopedicheskii slovar' kul'tury XX veka. Klyucherye ponyatiya i teksty [Encyclopedic dictionary of culture of the XX century. Key notions and texts]. Moscow: Agraf.

Ryabova, T. B. (2008a). Pol vlasti: gendernye stereotipy v sovremennoi rossiiskoi politike [The sex of the authority: Gender stereotypes in the modern Russian politics]. Ivanovo: Ivanovo State University.

Ryabova, T. B. (2008b). Gendernye stereotipy kak faktor otsenki sub»ektov politicheskogo protsessa [Gender stereotypes as a factor of evaluation of subjects of political process]. Zhenshchina $v$ Rossiiskom Obshchestve, 2, 44-52.

Sartre, J.-P. (1989). Ekzistentsializm - eto gumanizm [Existentialism is a humanism]. In A. A. Yakovlev (Ed.), Sumerki bogov [Twilight of the gods] (pp. 319-344). Moscow: Politizdat.

Schopenhauer, A. (1990). Aforizmy i maksimy [Aphorisms and maxims]. Leningrad: Leningrad State University.

Sell, R. L. (2007). Defining and measuring sexual orientation for research. In The health of sexual minorities: Public health perspectives on lesbian, gay, bisexual and transgender populations (pp. 355374). New York: Springer.

Semenova, V. (1998). Kachestvennye metody: Vvedenie v gumanisticheskuyu sotsiologiyu [Qualitative methods: An introduction to humanistic sociology]. Moscow: Dobrosvet.

Temkina, A. A. (2015). Gender, seks i feminizm: vzglyad sotsiologa [Gender, sex and feminism: The sociologist' view]. Retrieved from http://arzamas.academy/materials/959

Voronina, O. A. (2002). Gender [Gender]. In A. A. Denisova (Ed.), Slovar' gendernykh terminov [The vocabulary of gender terms] (pp. 21-24). Moscow: Informatsiya XXI vek.

Vorontsov, D. V. (2003). Sotsial'naya psikhologiya pola. Metodicheskie ukazaniya k spetskursu "Osnovy gendernoi psikhologii" [The social psychology of gender: Methodical guidelines to the special course "Foundations of gender psychology"]. Rostov-on-Don: Rostov State University.

Vorontsov, D. V. (2008). Gendernaya psikhologiya obshcheniya [The gender psychology of interaction]. Rostov-on-Don: Southern Federal University.

Wilson, G., \& Rahman, Q. (2005). Born gay: The psychobiology of sex orientation. London: Peter Owen Publishers.

Zdravomyslova, E. A., \& Temkina, A. A. (2015). 12 lektsii po gendernoi sotsiologii [12 lectures in gender sociology]. Saint Petersburg: European University at Saint Petersburg.

Dmitry D. Isaev - psychotherapist, "Scandinavia" clinic, MD, Ph.D.

E-mail: dr.disaev@gmail.com 